\title{
O comportamento dos usuários de bibliotecas em sistemas de informação
}

\author{
The behavior of the users of libraries in information systems
}

Patrícia Maria SILVIA'

\section{RESUMO}

presente trabalho pretende colaborar para o aprofundamento do conhecimento de algumas questões fundamentais no uso de sistemas de informação em bibliotecas. Busca compreender e identificar melhor os determinantes e barreiras de usabilidade, que leva à não interação usuário/sistema. $\bigcirc$ estudo foi conduzido a partir de um levantamento bibliográfico, comparando conceituações de pesquisadores da área, numa abordagem crítica.

Palavras-chave: sistemas de informação; usabilidade; estudos de usuário.

\section{ABSTRACT}

The present work intends to contribute for the deepening of the knowledge in some fundamental questions in the use of information systems in libraries. It tries to understand and identify the critical aspects and obstacles of the usability that interfere for the good interaction user/system. The study was a bibliographic survey, comparing conceptualizations of researchers in the area, in a critical approach.

Keywords: information systems; usability; user studies.

\section{INTRODUÇÃO}

Na recuperação da informação, vivemos a passagem da forma impressa para a forma digital, havendo a necessidade de desenvolver maneiras que permitam a difusão por meios acessíveis e simples de tais conteúdos informacionais. Em 1945, Vannevar Bush escreveu um artigo onde defendeu que seria importante armazenar o conhecimento convenientemente para que a raça humana avançasse como um todo, e propôs o projeto Memex - um dispositivo em que o indivíduo armazenaria seus livros, registros, suas anotações, suas comunicações. $\bigcirc$ dispositivo seria mecanizado de modo a poder ser consultado com extrema velocidade e flexibilidade (Bush, 1945).

Foi no início do século XX que surgiu a proposta de ampla conectividade, de preocupação com os conteúdos criados, manipulados e disseminados para os públicos mais diferenciados e heterogêneos, que chamamos de usuários (Marchiorl, 2002). A biblioteca, responsável pela criação e fornecimento de serviços e produtos de informação para os usuários (Mcgarry,

\footnotetext{
1 Mestranda, Ciência da Informação, Universidade Federal da Paraíba. João Pessoa, PB, Brasil. E-mail: < bibcrmpe@cremepe.org.br>. Recebido em 13/7/2007 e aceito para publicação em 31/1/2008.
} 
1999), mudou a forma de interação entre o profissional bibliotecário e o seu público, devido a essa nova proposta de conectividade.

Hoje, uma das maiores características da biblioteca conectada a sistemas de informação é o armazenamento eletrônico da informação, que a dissemina, independentemente de localização geográfica e física (Ramos, 2003). Com a introdução dessa nova tecnologia, quem ganha é o usuário, que terá suas incertezas resolvidas em um menor tempo.

Porém de nada adiantarão os sistemas de informação e suas tecnologias, se o principal favorecido, o usuário, não souber ou não quiser interagir com a informação disponibilizada em meios eletrônicos, criando-se assim, as chamadas barreiras de usabilidade de sistemas de informação em bibliotecas.

Neste estudo abordaremos algumas questões fundamentais para o entendimento e a importância do uso de sistemas de informação em bibliotecas, procurando entender o comportamento dos usuários desses sistemas.

\section{INFORMAÇÃO, SOCIEDADE E TECNOLOGIA}

Estamos vivendo em um mundo com complexas transformações, onde a informação é imprescindível para a sobrevivência e o desenvolvimento da sociedade. Surge então a necessidade de entendermos o que é informação e como usufruir dela.

Iniciaremos com uma definição não acadêmica do que venha a ser informação, porém precisamos fazer a distinção entre informação e dado, termos que são comumente confundidos como sinônimos.

Dado, por definição, é a informação em formato bruto, ou seja, o que não adquire sentido por si só, e conseqüentemente, não causa nenhuma transformação naquele que o recebe. A informação é o dado já lapidado, isto é, com sentido, de modo que traga alguma mudança ao individuo que o adquiriu. Quando são atribuídos aos dados valores, eles transformam-se em informação (Rezende; Abreu, 2003). Finalmente há o conhecimento, que é quando possuímos a informação e a utilizamos para um determinado propósito, colocando-a em prática. Para Silva (2004) uma informação é convertida em conhecimento quando um indivíduo consegue ligá-la a outras informações, avaliando-a e entendendo seu significado no interior de um contexto específico.

Dias et al (2004) afirmam que a informação é matéria prima para que os indivíduos participem das mudanças na realidade social, organizacional e na sua própria realidade. Então, podemos afirmar que a informação é o elo entre os dados não elaborados e o conhecimento adquirido. É afirmar que informação é a ponte dessa tríade, que tem início com um simples dado, sendo a informação a força motriz para se atingir o conhecimento.

Diversos autores conceituaram o que viria a ser informação, porém o que se pode observar é que esses conceitos estão entrelaçados por várias definições. Com Araújo (2002) o conceito de informação pode ser buscado através da etimologia da palavra: origem latina, do verbo informare, que significa dar forma, colocar em forma, criar, dar sentido. Machado (2003) assegura que na linguagem comum, o conceito de informação está sempre ligado ao significado, sendo usado como sinônimo de mensagem, notícia, fatos e idéias que são adquiridos e passados adiante como conhecimento.

No campo da Teoria da Informação é que se encontra o estudo da informação propriamente dito, introduzido por C. Shannon em 1948. Essa teoria foi alicerçada em um sistema de base matemática, cujo objetivo principal era estudar os problemas de transmissão de mensagens, a partir de um emissor até o receptor (Cohen, 2002). Foi formalizada no inicio do século XXe, naquele momento, o que preocupava era a quantidade de informação que um determinado canal suportava, a fim de corrigir e prever distorções na transmissão A informação, de acordo com essa teoria, depende de um processo de comunicação entre emissor-canal-receptor e se baseava num conjunto de teoremas, que buscava a maneira mais rápida, econômica e eficiente de enviar mensagens de um lugar para outro.

Sabemos que a informação é o insumo básico para as atividades humanas (Brandão, 2004), e que o processo de desenvolvimento humano ocorre em ondas, o que costumeiramente chamamos de revoluções: Revolução Agrícola, Revolução Industrial e Revolução tecnológica, na qual nos encontramos atualmente, que é marcada pela importância da informação no contexto 
da globalidade em que vivemos, também conhecida como Sociedade da Informação. Araújo (2001) estabelece que o produto do agora é a informação e o elemento fundamental desse produto é o ser humano.

$\mathrm{Na}$ Sociedade da Informação usa-se conhecimento para gerar conhecimento, deixando a informação de ser um fenômeno espontâneo e em grupos isolados para ser um fenômeno global. Tal sociedade não é caracterizada por um modismo e sim por mudanças, nas quais a informação disponível afetará a dinâmica nessa sociedade (Oliveira, 2004). Podemos caracterizar como uma mudança significativa o fato de que a Sociedade da Informação vive pela informação, sendo possível observar que se consome informação na embalagem, no design e, principalmente, vai-se ao consumo pela informação. Conforme Santos (2004), é o pós-modernismo, que invadiu nosso cotidiano, visando à sua saturação com informações, coisa típica das sociedades pós-industriais baseadas na informação. Pode-se afirmar que a Sociedade da Informação é pós-moderna, mobilizada pela informação e o consumo, e tem em seus pilares a tecnologia (Ferreira, 2003).

Foi em plena Revolução Industrial, porém, que surgiu a tecnologia, com a evolução das técnicas empregadas na época, impulsionadas pela competição e pela necessidade de criação de novos produtos (Garcia, 2001). A tecnologia foi diretamente relacionada com as inovações humanas, que se faziam necessárias, para o desenvolvimento a partir da era moderna.

A palavra tecnologia é de origem grega, vem do termo "techne": artefato, originalmente algo simplesmente esculpido, e "logos": pensamento ou razão, isto é, o estudo de algo. Vale salientar que a tecnologia influencia o trabalho intelectual e de pesquisa nas várias áreas do conhecimento, modificando as relações econômicas, políticas, culturais entre os grupos sociais.

\section{TECNOLOGIA DA INFORMAÇÃO, BIBLIOTECASE SISTEMAS DE INFORMAÇÃO}

Stébile (2001) afirma que o conceito de tecnologia da informação é bastante abrangente, porém a definição que considera a mais adequada é que a tecnologia da informação é tudo aquilo com que se pode obter, armazenar, tratar, comunicar e disponibilizar informação em meio digital. Segundo Cruz et al. (2003), com o surgimento da tecnologia da informação, a massa informacional deverá ser armazenada com ordem, de forma que nos sejam especificados satisfatoriamente os meios de disseminar os conteúdos dessas informações,; caso contrário, seremos esmagados sob o peso do dilúvio informacional.

Na era da informática, a utilização do computador para ordenar a informação gerada e registrada, bem como o tratamento computadorizado do conhecimento e da informação, foram as grandes respostas à explosão do novo século. Foi a partir daí que surgiram as tecnologias de informação, que são a utilização de recursos tecnológicos e computacionais para geração e disseminação da informação, são a forma computacional para manipular a informação.

A sociedade, hoje vive, com dois grandes problemas relacionados à informação: a grande quantidade gerada e a necessidade de controlá-la. Afirma Machado (2003) que o cérebro humano não suporta o peso desse conhecimento acumulado e registrado em diferentes suportes. As bibliotecas, além de possuir a função de organizadoras dos saberes e de sistematização do acesso à informação, passam a atuar como centros de educação, recreação e pesquisa. São reconhecidas como espaços informativos, para conhecer, discutir, criar e recriar, disponibilizando informações de maneira rápida e eficaz, ou seja, caracterizando-se pelas soluções qualitativas, que implicam redução de tempo e de precisão dos serviços.

Quanto mais o homem gera documentos, mais as bibliotecas buscam instrumentos e técnicas que permitam a recuperação desses documentos. Quanto mais uma biblioteca propicia uma multiciplidade de informações, mais ela estará chegando ao seu objetivo (Milanesi, 1983). As novas tecnologias implementadas em bibliotecas, poderoso instrumento de comunicação que diminui as distâncias, fizeram com que rompessem com o modelo tradicional, o acervo físico. Os grandes benefícios que as tecnologias de informação proporcionam às bibliotecas são: racionalidade no trabalho, aumento de produção, melhor controle e uma maior facilidade de armazenamento e disseminação da informação (Ramos, 2003). Para Machado (2003), a aplicação da informática nesse processo de crescimento da informação foi o grande propulsor do surgimento de sistemas de informação em bibliotecas.

Antes de explicarmos o conceito de sistema de informação, é imprescindível que façamos uma pequena 
explanação com relação à origem dos sistemas. A gênese dos sistemas se deu em 1950, época em que começaram a ser estudados, sob o impulso do biólogo alemão Ludwig von Bertalanffy, com a chamada Teoria Geral dos Sistemas. Bertalanffy, pesquisando o comportamento dos organismos vivos, constatou que, mesmo com as variedades de formas e características, eles possuíam pontos em comum (Oliveira, 2004; Rezende, 2003; Stair, 2002).

A Teoria Geral dos Sistemas fundamenta-se em três premissas básicas: 1. Os sistemas existem dentro dos sistemas, porque as moléculas estão dentro das células, as células dentro dos tecidos, os tecidos dentro dos órgãos e assim por diante; 2 . Os sistemas são abertos - como uma decorrência da premissa anterior -, caracterizados por um processo de intercâmbio infinito com seu ambiente, que são os outros sistemas e finalmente 3. As funções de um sistema dependem de sua estrutura, pois os sistemas são interdependentes: à medida que suas funções se contraem ou expandem, sua estrutura acompanha.

Em sentido geral, sistema significa, segundo Japiassú (2001), Doron e Parot (1998), um conjunto de elementos ou partes interdependentes que constituem uma totalidade organizada, de acordo com determinados princípios. Podemos considerar que um sistema é basicamente um conjunto de elementos ou componentes em interação para cumprimento de metas (Stair; Reynolds, 2002).

Rezende (2003) afirma que a composição moderna dos sistemas ultrapassa a convenção simplória e antiga de entrada, processamento e saída. Os sistemas hoje são compostos basicamente por: objetivos entradas - transformações - saídas - feedback. Nessa estrutura, os objetivos são a razão de existir do sistema, a finalidade para a qual o sistema foi criado; as entradas têm a função de fornecer ao sistema o material para a operação que gerará as saídas, as quais deverão estar em sintonia com os objetivos do sistema; as transformações são o processador, a maneira pela qual os componentes interagem no sentido de produzir saídas desejadas. É nessa etapa que o insumo (entradas) se transforma em produto (saídas); as saídas correspondem aos resultados do processo de transformação, e devem ser coerentes com os objetivos do sistema; e o feedback, considerado sinalizador e regulador dos mecanismos de entrada, transformação e saída do sistema. É utilizado para fazer ajustes ou modificações nas atividades do sistema.
De forma clara e objetiva, Stair e Reynolds (2002) exemplificam o que viria a ser a composição moderna de um sistema. Vamos considerar um lava-jato, cujo objetivo principal seria a lavagem do carro de forma rápida. As entradas tangíveis para o processo são: um carro sujo, a água e os ingredientes de limpeza, tempo, energia, entre outras; as transformações consistiriam em selecionar as opções de limpeza, se com lavagem simples ou completa, etc.; a saída é um carro limpo e, finalmente, denominaríamos como o mecanismo de feedback a avaliação do cliente quanto à limpeza do carro.

A partir do exposto anteriormente, poderemos definir o que venha a ser um sistema de informação. É um sistema baseado em informações, ou seja, a sua matéria prima é a informação, podendo ser tecnicamente definido como um conjunto de componentes inter-relacionados que coleciona ou recupera, processa e distribui informação. $\bigcirc$ sistema de informação pode ser manual ou computadorizado, e, nos dois casos, o elemento indispensável ao bom funcionamento do sistema é o individuo, pois é ele que concebe, programa, gerencia, executa e mantém o sistema; assim, a partir desse processo, existirá a seleção e a organização das informações para a sua efetiva utilização.

As características do sistema de informação são: ele deve ser fácil de usar, flexível nos ajustamentos, confiável nas informações geradas e rentável, de modo que os custos justifiquem os benefícios oferecidos. As vantagens e uso dos sistemas de informação ajudam tanto em termos pessoais como profissionais. Todo sistema de informação tem algum grau de relacionamento e de dependência com o ambiente, pois qualquer atividade desempenhada ele pode ser desempenhada manualmente, porém o tempo gasto no trabalho manual acarretaria custo proibitivo.

\section{COMPORTAMENTO DOS USUÁRIOS DE BIBLIOTECAS EM SISTEMAS DE INFORMAÇÃO}

As relações homem-computador têm sido objeto de profundas reflexões e estudos em função das novas tecnologias para processamento e disseminação da informação e de sua influência no comportamento da sociedade em que vivemos, é o que afirma Heemann (1997). 
Os sistemas de informação em bibliotecas surgiram com a intenção de auxiliar os usuários na difícil tarefa de recuperar informação. Tendo em vista que, cada vez mais, os sistemas de informação estão presentes em nossas bibliotecas, é importante treinamentos para a aceitação e a implementação de novas políticas nas bibliotecas (Stair; Reynolds, 2002). Apesar de muitas bibliotecas já possuírem em seus procedimentos treinamentos com seu público-alvo, ainda não é o suficiente para que os usuários se sintam confortáveis na busca da informação desejada por meio da tecnologia.

Para podermos identificar quais as dificuldades encontradas na interação usuário/sistemas, resolvemos classificar os usuários da seguinte maneira: os considerados principiantes, que são os que merecem maior atenção e acompanhamento dos bibliotecários; e um outro grupo, que são os instruídos, no qual a contribuição é significativa nas atividades de inovação e planejamento do sistema. Sendo principiantes e instruídos, eles ainda não se sentem confortáveis na busca pela informação desejada por meio dos sistemas de informação.

Afirma Figueiredo (1987) que os usuários de sistemas de informação têm reagido como qualquer pessoa que tem que se defrontar com uma nova idéia. Na verdade, o que os usuários realmente querem é que suas expectativas de informação sejam atendidas, não importando o formato de recuperação da pesquisa e nem quem a executa, segundo Garcez e Rados (2002).

É importante perceber que o processo de criação dos sistemas deve ser centrado nos usuários, e sua interface precisa ser projetada com o objetivo de satisfazer as necessidades dos usuários. Nem sempre, porém, essa preocupação é observada, pois na maioria das criações dos sistemas, as atenções estão voltadas à elegância das tecnologias empregadas, e, conseqüentemente, ao pouco uso estratégico e a adequação ao usuário final (Stébile, 2001). Um bom exemplo dessa afirmação é citar Machado (2003) que se refere à quantidade de referências bibliográficas resgatadas em uma busca no sistema, que muitas vezes excede as possibilidades do usuário de convertê-la em informação.

Sabemos que as inovações tecnológicas nas bibliotecas produzem transformações profundas na vida cotidiana dos usuários. Tal fato se deve à grande quantidade de informação disponibilizada em vários suportes, o que dificulta a filtragem do que realmente interessa, e, principalmente, à perceptível atenção dada aos computadores (software) e na pouca atenção dada aos seres humanos (usuários). Para Agner (2004), o problema da interação usuários versus sistemas e da subutilização dessas tecnologias surge a partir desse entendimento.

Segundo Rezende e Abreu (2003), os hábitos individuais são outra forma de bloqueio à inovação. Para os autores, esses desperdícios e erros, na arquitetura dos sistemas, que mexe na relação usuáriosmáquina, não são os únicos causadores das barreiras de usabilidade em sistemas de informação. $O$ comportamento dos usuários também contribui com uma parcela significativa nesse processo de interação.

Para maior entendimento do comportamento do usuário de informação em bibliotecas, por meio dos sistemas, é primordial entender o que venha a ser usabilidade, a fim de se perceberem as barreiras. Usabilidade é a característica que determina se o manuseio de um produto é fácil e rapidamente aprendido, com quantidade pequena de erros operacionais e oferecimento de um alto grau de satisfação, atingindo seus objetivos (Ferreira; Leite, 2003; Lira, 2005; ). O conceito não é novo e sua origem está ligada à ergonomia.

Em se tratando de sistemas de informação, Vidotti e Sanches (2004) estabeleceram suas características de usabilidade:

Eficácia e eficiência de uso - o sistema deve ser eficiente a ponto de permitir que o usuário, tendo aprendido a interagir com ele, atinja níveis altos de produtividade na realização de suas tarefas;

Satisfação subjetiva - o usuário considera agradável a interação com o sistema e se sente subjetivamente satisfeito com ele;

Facilidade de aprendizado - o sistema deve ser fácil de aprender, de tal forma que o usuário consiga rapidamente explorá-lo e realizar suas tarefas com ele. Em geral, um sistema é considerado de fácil aprendizado quando usuários inexperientes conseguem atingir um certo grau de proficiência em um curto período de tempo;

Facilidade de memorização - após um certo período sem utilizá-lo, o usuário não freqüente é capaz de retornar ao sistema e realizar suas tarefas, sem a necessidade de reaprender como interagir com ele; 
Baixa taxa de erros - em um sistema com baixa taxa de erros, o usuário é capaz de realizar tarefas sem maiores transtornos, recuperando erros, caso ocorram;

Consistência - tarefas similares requerem seqüências de ações similares, assim como ações iguais devem acarretar efeitos iguais. Usar terminologia, leiaute gráfico, conjuntos de cores e de fontes padronizados também são medidas de consistência;

Flexibilidade ou feedback - refere-se à variedade de formas com que o usuário e o sistema trocam informações. Esse atributo diz respeito à capacidade do sistema de se adaptar ao contexto e às necessidades e preferências do usuário, tornando seu uso mais eficiente. Em função da diversidade de tipos de usuários de um sistema interativo, é necessário que sua interface seja flexível o bastante para realizar a mesma tarefa de diferentes maneiras, de acordo com o contexto e com as características de cada tipo de usuário.

Para Oliveira (2004) os sistemas que tendem a incomodar ou frustrar os usuários não podem ser sistemas eficazes, seja qual for seu grau de elegância técnica e de eficácia no processamento de dados. Tal afirmação remete-nos a Lei de Mooers, que fala que um sistema de informação não será usado se for mais difícil obter a informação do que não obtê-la (Dias, 2002; Saracevic, 1996).

A aceitação e o uso de tecnologias da informação é um assunto que tem recebido a atenção de pesquisadores e profissionais há mais de uma década (Venkatesh, 2003). Com o intuito de buscar melhorias constantes aos sistemas de informação e ao seu uso, alguns estudiosos da área da interface homem-máquina propuseram vários testes e métodos de avaliar o uso e comportamento dos usuários quanto à aceitação e ao uso de tecnologia de informação e de sistemas de informação. São os chamados modelos teóricos de avaliação e uso de sistemas de informação, cada um competindo entre si e com jogos diferentes de determinantes de aceitação.

As pesquisas associadas à adoção de tecnologias da informação, bem como da avaliação dos seus impactos são atividades importantes na investigação de sistemas de informação, quer se trate de contextos organizacionais, quer se trate da sociedade. Conseqüentemente, as companhias e a sociedade necessitam desenvolver não apenas uma cultura geralmente favorável, mas características culturais específicas que maximizem o uso da tecnologia no desempenho de seus empregados e no seu dia-adia.

Os estudos baseados na problemática de uso em sistemas começaram a partir da década de 80, por F. D. Davis, pesquisador em sistemas de informação. Davis propôs um modelo que auxiliasse e previsse o uso dos sistemas, desenvolvendo o Technology Acceptance Model - TAM, modelo de aceitação de tecnologia (Davis, 1989). Esse estudo de Davis sugere que os indivíduos usarão a tecnologia se acreditarem que esse uso fornecerá resultados positivos, focalizandose na facilidade de uso percebida e na utilidade percebida. Assim, o TAM normalmente é utilizado para entender o porquê de o usuário aceitar ou rejeitar a tecnologia de informação e como melhorar a aceitação, oferecendo, desse modo, um suporte para prever e explicar a aceitação.

Segundo Dias et al. (2003), alguns autores abordam o comportamento dos usuários com relação à não-aceitação da tecnologia como uma questão de resistência às mudanças, sem entender, contudo, os motivos de tal resistência. Porém conforme explica Maia e Cendón (2005), existem outros fatores que também comprometem o comportamento do usuário, como, por exemplo, a habilidade técnica específica desse usuário, influenciando diretamente na utilização dos sistemas, assim como o contexto e o espaço onde a pessoa desenvolve o uso.

Apesar do importante corpo de investigação associado à adoção de tecnologias da informação, tais investigações ainda não conseguem explicar todos os fenômenos que lhe estão associados. Tal fato se deve, por um lado, à complexidade dos processos de adoção - principalmente porque envolvem pessoas e interferem nas suas percepções de natureza cognitiva, as quais nem sempre se regem por interesses organizacionais, antes são afetadas por questões de natureza individual e cultural -, e, por outro lado, à natureza fortemente dinâmica e evolutiva das tecnologias da informação, mudando muito rapidamente os paradigmas tecnológicos e criando novos campos de investigação.

A seguir, listamos algumas barreiras mencionadas na literatura com relação à usabilidade em sistemas de informação pelo usuário: 
1. Barreiras socioeconômicas - A miséria talvez seja a pior das nossas mazelas, e a reprodução da miséria se dá com a combinação de três elementos: a falta de crédito, a deficiência educacional e a carência de tecnologia (Santos, 2002-2005). Compreende-se aqui o outro lado da Sociedade da Informação, que é a Sociedade da Desinformação, do analfabetismo tecnológico. $\bigcirc$ Governo deve promover a universalização do acesso e o uso dos meios eletrônicos de informação, a chamada alfabetização digital (Takahashi, 2000). Caso contrário, a população com escassos recursos financeiros não poderá usufruir os benefícios tecnológicos.

2. Barreiras Tecnológicas - Aqui poderíamos citar a chamada lei do menor esforço ou princípio do menor esforço, que estabelece que nenhum sistema de informação é utilizado se não for de fácil acesso e de facilidade de uso (Figueiredo, 1987). Essa lei tem duas faces: uma é o fato de o sistema não ser acessível, como já foi mencionado, e a outra diz respeito ao comodismo dos usuários, que preferem que suas consultas sejam feitas pelo profissional bibliotecário, sem sequer tentarem uma aproximação com o sistema.

3. Barreiras Psicológicas - Dizem respeito ao próprio usuário, como afirma Figueiredo (1987), o qual pode trazer a sua própria autopercepção dos serviços e produtos - se o usuário acredita que o sistema é eficiente, então, para ele, o sistema é eficiente, e o oposto é também verdadeiro. Trazem preconceitos e comportamentos pessoais na busca pela informação e essa reação, para Rezende e Abreu (2003) geralmente vem acompanhada pela inabilidade de acompanhar as mudanças causadas pelo computador de modo saudável. É a cyberphobia, o medo do computador e de coisas ligadas a ele.

4. Barreiras Institucionais - Figueiredo (1987) esclarece que são aquelas criadas ou existentes no próprio sistema, tais como: coleções deficientes e defasadas, sistema sem manutenção técnica, normas restritas ao uso, pessoal, sem treinamento apropriado.
Para dirimir algumas das barreiras expostas acima, a capacitação no uso seria uma das grandes respostas. Para tanto, é necessário conhecer o usuário dessa informação, e, conseqüentemente, as necessidades que ele possui.

Já sabemos que um dos objetivos específicos dos sistemas de informação é minimizar o tempo de busca do usuário numa determinada pesquisa. Conforme Garcez e Rados (2002), a formulação dessa estratégica de busca deve requerer conhecimento do assunto pesquisado, do sistema e da bibliografia, portanto deve ser feita pelo usuário ou bibliotecário. A partir dessa afirmação, é compreensível que tanto o usuário como o bibliotecário deverão ser capacitados, de modo que estejam em sintonia com o sistema, a fim de que haja a eficácia e eficiência de uso.

A pesquisa em sistema de informação busca a criatividade de quem a executa. $\bigcirc$ primeiro passo é definir o que se procura, seguido de como procurar, selecionando-se o que interessa e, posteriormente, combinar esses dados para se atingir o objetivo esperado. A busca em um sistema levará o usuário a um conjunto de conflitos e reforços de informações, muito mais de reforços, e abrir-se-á um leque de oportunidades de dados para se atingir ao conhecimento. Cabe ao bibliotecário também saber usar para orientar. Para Jambeiro e Silva (2004), o pesquisador/usuário ganhou uma autonomia, um self service informacional: quem precisa pega sem esperar ser servido, objetivo maior da capacitação.

\section{CONCLUSÃO}

Como foi observado ao longo do texto, enfatizou-se a importância da informação em nossa sociedade, o ritmo acelerado da produção, a qual se acumula desordenadamente. Com o advento da tecnologia da informação, que veio para racionalizar a enxurrada de informações com a criação dos sistemas, desenvolveram-se novos métodos computacionais de armazenamento, organização e disseminação dessa informação.

As mudanças pelas quais as bibliotecas passaram e vêm passando, ao longo do tempo, com as inovações tecnológicas, exigem implantação de novas infra-estruturas compatíveis com a demanda crescente de informações. $\bigcirc$ usuário, razão de ser da 
biblioteca, logo sentiu as transformações impostas pela tecnologia da informação. As barreiras comportamentais que essas inovações tecnológicas causaram, fossem elas de ordem tecnológica, psicológica, socioeconômica e/ou institucional, refletiram-se diretamente no uso e na busca de informação por meio dos sistemas de informação utilizados nas bibliotecas.

Não se tem nenhuma dúvida de que a capacitação dos usuários no manuseio dos sistemas de informação em bibliotecas é extremamente importante e necessária. É, pois, a partir dessa intimidade com o sistema, que o usuário descobrirá novas informações, além daquelas que ele deseja, num processo que lhe dará várias oportunidades de novos conhecimentos. O usuário, além de conhecer o sistema, deverá estar apto a localizar, selecionar e utilizar as fontes mais adequadas para realização de uma busca pertinente e eficaz.

A biblioteca poderá ter sua função e espaço ampliado pelo dinamismo do profissional bibliotecário, seja como orientador no uso do sistema de informação, seja como executor da pesquisa. Tarapanoff, Suaiden e Oliveira (2004), explica que os cientistas da informação devem ser mediadores entre o mundo digital e a capacidade real de entendimento do receptor da informação, garantindo a efetiva comunicação e a satisfação da necessidade informacional do usuário dessa tecnologia. Cunha (2003) acrescenta que o profissional da informação é um ser essencialmente social, um ser de mediação e contato, capaz de fazer com o outro e de fazer para o outro. Levando-se em consideração o que Geertz (1997) afirma, o maior obstáculo é a dificuldade em fazer com que pessoas que vivem em mundos diferentes possam influenciar-se reciprocamente de uma forma genuína, partindo do pressuposto de que exista uma consciência coletiva, a qual consiste na interação de múltiplas perspectivas.

Não devemos esquecer que, paralela à Sociedade da Informação - aquela onde há usuários capazes de trafegar pelas infovias, tendo total autonomia na busca de seus próprios caminhos, definindo os atalhos preferidos -, há também a Sociedade da Desinformação, uma sociedade de maior proporção, do analfabetismo digital e dos excluídos tecnológicos. A figura do profissional da informação deverá, então, ocupar um importante espaço no hiato existente entre essas duas sociedades, sendo o ponto de interseção.

\section{REFERÊNCIAS}

AGNER, L. Arquitetura de informação: testes de usabilidade. 2004. Disponível em: < http://webinsider.uol.com.br/index.php/ 2004/01/06/arquitetura-de-informacao-testes-de-usabilidade/ >. Acesso em: 15 fev. 2005.

ARAÚJO, A.C.M. A informação como fator diferenciador para o sucesso estratégico das organizações. 2001. Disponível em: <http://www.informal.com.br/pls/portal/docs/PAGE/ GESTAODOCONHECIMENTOINFORMALINFORMATICA/ ARTIGOSGESTAODOCONHECIMENTO/ARTIGOSGC/ ARTIGO_100902.PDF> . Acesso em: 15 fev. 2005.

ARAUJO, E.A. O fenômeno informacional na ciência da informação: abordagem teórica-conceitual. In: CASTRO, C. Ciência da informação e biblioteconomia: múltiplos discursos. São Luiz: EDUFMA, 2002. p.11-34.

BRANDÃO, W.C. A Internet como fonte de informação para negócios: um ensaio sobre a realidade da internet brasileira. Perspectiva em Ciência da Informação, v.9, n. 1, p. 88-99, 2004.

BUSH, V. As we may think. Atlantic Monthly, v. 176, n. 1, p. 101 108, 1945. Disponivel em: <http://www.theatlantic.com/ doc.194507/bush>. Acesso em: 14. ago. 2007.
COHEN, M.F. Alguns aspectos do uso da informação na economia da informação. Ci. Inf., v. 31, n. 3, p. 26-36, 2002.

CRUZ, A.A.A.C.; et al. Impacto dos periódicos eletrônicos em bibliotecas universitárias. Ci. Inf., v.32, n.2, p. 47-53, 2003.

CUNHA, M.V. O papel social do bibliotecário. Enc. Bibli: R. Eletr. Bibliotecon. Ci. Inf., n. 15, p. 1-6, 2003.

DAVIS, F.D. Perceived usefulness, perceived ease of use and user acepptance of information technology. Mis Quarterly, v. 13, n.3, p.319-340, 1989.

DIAS, M.M.K. et al. Capacitação do bibliotecário como mediador do aprendizado no uso de fontes de informação. Revista Digital de Biblioteconomia e Ciência da Informação, v.2, n. 1, p.1-16, 2004. Disponível em: <http://server01.bc.unicamp.br/ seer/ojs/viewarticle. php? id=22\&layout=abstract $>$. Acesso em: 15 maio 2005.

DIAS, M.C. et al. Análise do modelo de aceitação de tecnologia de Davis. R. Spei, v.4, n.2, p. 15-23, 2003. 
DIAS, G.A. Periódicos eletrônicos: considerações relativas à aceitação deste recurso pelos usuários. Ci. Inf., v. 31, n. 3, p. 18-25, 2002.

DORON, R.; PAROT, F. Dicionário de psicologia. São Paulo: Ática, 1998. $863 p$

FERREIRA, R.S. A sociedade da informação no Brasil: um ensaio sobre os desafios do Estado. Ci. Inf., v.32, n. 1, p.36-41, 2003.

FERREIRA, S.B.L.; LEITE, J.C.S.P. Avaliação da usabilidade em sistemas de informação: o caso do sistema submarino. RAC: Revista de Administração Contemporânea, v.7, n.2, p. 115-136, 2003.

FIGUEIREDO, N.M. Da necessidade de promover o uso da informação. Ci. Inf., v.6, n.1, p.75-79, 1987.

GARCEZ, M.S.; RADOS, G.J. Varvakis. Biblioteca híbrida: um novo enfoque no suporte à educação à distância. Ciência da Informação, v.31, n.2, p.44-51, 2002.

GARCIA, J.C.R. Transmissão de tecnologia: análise do conceito. DataGramaZero: Revista de Ciência da Informação, v.2, n.2, 2001. Disponível em: <http://www.dgz.org.br/abr0l/ F I art.htm >. Acesso em: 15 ago. 2005.

HEEMANN, V. Avaliação ergonômica de interfaces de bases de dados por meio de checklist especializado. 1997. f. Dissertação (Mestrado em Engenharia de Produção) - Universidade Federal de Santa Catarina, Florianópolis, 1997. Disponível em: <http://www.eps.ufsc.br/disserta97/heemann/>. Acesso em: 15 maio 2005

JAMBEIRO, O.; SILVA, H.P. A informação e suas profissões: a sobrevivência ao alcance de todos. DataGramaZero: Revista de Ciência da Informação, v.5, n.4, 2004. Disponível em: <http:/ /www.dgz.org.br/ago04/Art_03.htm>. Acesso em: 15 maio 2005.

JAPIASSÚ, H. Dicionário básico de filosofia. 3.ed. Rio de Janeiro: Jorge Zahar, 2001. 296p.

LIRA, M. Você já ouviu falar no termo usabilidade? Diário de Pernambuco, 13 abr. 2005. Caderno de Informática. Disponível em: <http://www.pernambuco.com/diario/2005/04/13/ infol1_0.asp>. Acesso em: 13 abr. 2005.

MACHADO, A.M.N. Informação e controle bibliográfico: um olhar sobre a cibernética. São Paulo: UNESP, 2003. 159p.

MAIA, L.C.G.; CENDÓN, B.V. Um estudo sobre o uso de sistemas de recuperação de informação: o portal de periódicos CAPES na UFMG. In: SIMPÓSIO MINEIRO DE SISTEMAS DE INFORMAÇÃO, 2., 2005. Belo Horizonte. Anais... Belo Horizonte:[s.n], 2005.

MARCHIORI, P.Z. A ciência e a gestão da informação: compatibilidade no espaço profissional. Ci. Inf., v.31, n.2, p.72-79, 2002.
McGARRY, K. O contexto dinâmico da informação: uma análise introdutória. Brasília: Briquet de Lemos, 1999.

MILANESI, L. O que é biblioteca. São Paulo: Brasiliense, 1983. 107p. (Coleção Primeiro Passos; 94).

OLIVEIRA, J.F. Sistemas de informação versus tecnologia de informação: um impasse empresarial. São Paulo: Érica, 2004. $140 \mathrm{p}$.

RAMOS, M.C.L. A utopia dos bits: impacto das tecnologias de informação na interação bibliotecário/usuário (de graduação) da biblioteca universitária da Universidade Federal de Santa Catarina. 2003. 176f. Dissertação (mestrado em Engenharia de Produção) - Universidade Federal de Santa Catarina, Florianópolis, 2003

REZENDE, D.A.; ABREU, A.F. Tecnologia da informação aplicada a sistemas de informação empresariais: o papel estratégico da informação e dos sistemas de informação nas empresas. 3. ed. São Paulo: Atlas, 2003. 316 p.

SANTOS, J.F. O que é pós-moderno. São Paulo: Brasiliense, 2004. 111 p. (Coleção Primeiro Passos; 165)

SANTOS, N.C. Ainfo-barreira. 2002-2005. Disponível em: <http:/ /www.cidade.usp.br/arquivo/artigos/index1301.php\#rodape>. Acesso em: 15 maio 2005.

SARACEVIC, T. Ciência da Informação: origem, evolução e relações. Perspectiva em Ciência da Informação, v. 1, n. 1, p.41-62, 1996.

SILVA, S.L. Gestão do conhecimento: uma revisão crítica orientada pela abordagem da criação do conhecimento. Ci. Inf., v. 33, n.2, p.143-141, 2004

STAIR, R.M.; REYNOLDS, G.W. Princípios de sistemas de informação: uma abordagem gerencial. 4.ed. Tradução Alexandre Melo de Oliveira. Rio de Janeiro: LTC, 2002. 496p.

STÉBILE, S. Um estudo sobre a desconexão entre usuários e desenvolvedores de sistemas de informação e sua influência na obtenção de informação pelo decisor. 2001. 163 f. Dissertação (Mestrado em Engenharia de Produção) - Universidade de São Paulo, São Paulo, 2001

TAKAHASHI, T. (Org.). Sociedade da informação no Brasil: livro verde. Brasília: Ministério da Ciência e Tecnologia, 2000. 195p.

VENKATESH, V. et al. User acceptance of information technology: toward a unified view. Mis Quarterly, v.27, n.3, 2003.

VIDOTTI, S.A.B.G.; SANCHES, S.A. Arquitetura da informação de web sites. 2004. Disponível em: <http://libdigi.unicamp.br/ document/?view=8302>. Acesso em: 15 jun. 2005. 
